\title{
Model for Quantitative Analysis of Phosphorus Removed during Leaching of Iron Oxide Ore in Oxalic Acid Solution
}

\author{
C. I. Nwoye ${ }^{1}$, C. N. Mbah $^{2}$, C. C. Nwakwuo ${ }^{3}$ and A. I. Ogbonna ${ }^{1}$ \\ ${ }^{1}$ Department of Materials and Metallurgical Engineering, Federal University of Technology, \\ P. M. B 1526, Owerri, Imo State, Nigeria. \\ ${ }^{2}$ Department of Materials and Metallurgical Engineering. Enugu State University of Science and \\ Technology, P. M. B 01660, Enugu State, Nigeria. \\ ${ }^{3}$ Department of Material Science, Oxford University, United Kingdom. \\ *Corresponding Author: chikeyn@yahoo.com
}

\begin{abstract}
Model for quantitative analysis of the concentration of phosphorus removed (relative to the final $\mathrm{pH}$ of the leaching solution) during leaching of iron oxide ore in oxalic acid solution has been derived. It was observed that the validity of the model is rooted in the expression $\ln P=(\gamma+N \ln \gamma)$ where $P$ is the concentration of phosphorus removed during the leaching process, $N$ is 0.57; dissolution coefficient of phosphorus in oxalic acid solution, and $\gamma$ is the final $\mathrm{pH}$ of the leaching solution at the time $t$, when the concentration of phosphorus is evaluated, and both sides of the expression are correspondingly approximately equal. The model;

$$
P=e^{(\gamma+0.57 \ln \gamma)}
$$

depends on the value of the final pH of the leaching solution which varies with leaching time. The maximum deviation of the model-predicted concentration of removed phosphorus from the corresponding concentration obtained from the experiment was less than 22\%. The concentrations of phosphorus removed per unit mass of iron oxide ore added as obtained from experiment and derived model are 3.8329 and $4.0614 \mathrm{mg} / \mathrm{kg} / \mathrm{g}$ respectively which are in proximate agreement.
\end{abstract}

Keywords: Model, Quantitative Analysis, Phosphorus Removed, Oxalic Acid, Iron Oxide Ore, Leaching. 


\section{INTRODUCTION}

Several works [1-6] have been carried out to remove phosphorus from steel during steel making. All these works carried out, pointed out low treatment temperature and high oxygen activity as the only essential and unavoidable process conditions which can enhance the rate of dephosphorization. High activity of $\mathrm{CaO}$; a product of decomposition of $\mathrm{CaCO}_{3}$ and a slag forming material is required for enhancement of the dephosphorization process with the phosphorus forming part of the slag. This process involves pyrometallurgy and is capital intensive.

It has been reported [7] that the removal of phosphorus from iron can be achieved only by oxidation during steel making, under a basic slag.

Nwoye [8] derived a model for predicting the time for dissolution of pre-quantified concentration of phosphorus during leaching of iron oxide ore in oxalic acid solution as:

Where

$$
\tau=\left(\frac{\log \left(\frac{\mathrm{P}^{1 / 4}}{1.8}\right)}{\log \mathrm{T}}\right)
$$

$\mathrm{T}=$ Leaching temperature $\left({ }^{0} \mathrm{C}\right)$ in the experiment [9], taken as specified leaching temperature $\left({ }^{0} \mathrm{C}\right)$ aiding the expected dissolution of phosphorus .

$\mathrm{N}=1.8$ (Dissolution coefficient of phosphorus in oxalic acid solution during leaching of iron oxide ore) determined in the experiment [9].

$\mathrm{P}=$ Concentration of dissolved phosphorus $(\mathrm{mg} / \mathrm{Kg})$ in the experiment [9], taken as pre-quantified concentration of phosphorus expected to dissolve after a leaching time $t$ $(\mathrm{mg} / \mathrm{Kg})$ in the model.

$\tau=$ Leaching time (sec.) in the experiment [9], taken as time for dissolution of the prequantified concentration of phosphorus (hrs) in the model.

The model was found to depend on a range of specified leaching temperatures $\left(45-70^{\circ} \mathrm{C}\right)$ for its validity. It was found [9] that the time for dissolution of any given concentration of phosphorus decreases with increase in the leaching temperature (up to $70^{\circ} \mathrm{C}$ ), at initial $\mathrm{pH} 5.5$ and average grain size of $150 \mu \mathrm{m}$.

Nwoye et al. [10] also formulated a model for predicting the concentration of phosphorus removed during leaching of iron oxide ore in oxalic acid solution. The model is expressed as;

$$
\mathrm{P}=150.5 / \mu \alpha
$$

It was found to predict the removed phosphorus concentration, with utmost dependence on the final $\mathrm{pH}$ of the leaching solution and weight input of the iron oxide ore. The model indicates that the concentration of phosphorus removed is inversely proportional to the product of the weight input of the iron oxide ore and the final $\mathrm{pH}$ of the leaching solution. Process conditions considered during the formulation of the model [10] include: leaching temperature of $25^{\circ} \mathrm{C}$, initial solution pH 5.5 and average ore grain size; $150 \mu \mathrm{m}$ ). 
Nwoye [11] derived a model for the evaluation of the concentration of dissolved phosphorus (relative to the final $\mathrm{pH}$ of the leaching solution) during leaching of iron oxide ore in oxalic acid solution. It was observed that the validity of the model is rooted in the relationship $\ln \mathrm{P}=\mathrm{N} / \alpha$ where both sides of the expression are approximately equal to 4 . The model expressed as;

$$
\mathrm{P}=\mathrm{e}^{(12.25 / \alpha)}
$$

depends on the value of the final $\mathrm{pH}$ of the leaching solution which varies with leaching time. In all, the positive or negative deviation of the model-predicted phosphorus concentration from its corresponding value obtained from the experiment was found to be less than $22 \%$.

Nwoye [12] also derived a model for predicting the concentration of phosphorus removed during leaching of iron oxide ore in oxalic acid solution. The model is expressed as;

$$
\mathrm{P}=\left[\left(1.8(\mathrm{~T})^{\tau}\right)\right]^{4}
$$

was found to be dependent on leaching temperature ranging from $45-70^{\circ} \mathrm{C}$ and specified leaching time of $0.1381 \mathrm{hr}(497 \mathrm{secs}$.) recorded during experiment, for its validity. It was found that the validity of the model is rooted in the expression $\left(\mathrm{P}^{1 / 4}\right) / \mathrm{N}=(\mathrm{T})^{\tau}$ where both sides of the expression are correspondingly almost equal. The maximum deviation of the model-predicted values of $\mathrm{P}$ from the corresponding experimental values was found to be less than $29 \%$ which is quite within the range of acceptable deviation limit of experimental results.

Model for predictive analysis of the concentration of phosphorus removed (relative to the initial and final $\mathrm{pH}$ of the leaching solution) during leaching of iron oxide ore in sulphuric acid solution has been derived by Nwoye and Ndlu [13]. It was observed that the validity of the model is rooted in the mathematical expression; $(\mathrm{P} / \mathrm{N})^{1 / 3}=\left(\mathrm{e}^{\gamma / \alpha}\right)$ where both sides of the relationship are almost equal. The model;

$$
\mathrm{P}=4.25\left(\mathrm{e}^{\gamma / \alpha}\right)^{3}
$$

shows that the concentration of phosphorus removed is dependent on the values of the initial and final $\mathrm{pH}$ of the leaching solution.

Biological processes for phosphorus removal have also been evaluated based on the use of several types of fungi, some being oxalic acid producing. Anyakwo and Obot [14] recently presented their results of a study on the use of Aspergillus niger and their cultural filtrates for removing phosphorus from Agbaja (Nigeria) iron oxide ore. The results of this work [14] show that phosphorus removal efficiencies at the end of the 49 days of the leaching process are 81,63 and $68 \%$ for 5, 100 and 250 mesh grain sizes respectively.

An attempt has been made in the past [15] to leach Itakpe iron oxide ore using oxalic acid solution in order to determine the maximum concentration of phosphorus that is removable. Results of chemical analysis of the ore indicate that the percentage of phosphorus in the ore is about $1.18 \%$, which from all indication is quite high and likely to affect adversely the mechanical properties of the steel involved; hence the need for dephosphorization. It was reported [15] that phosphorus can be removed from this iron oxide ore through a process associated with hydrometallurgy. Phosphorus was removed at a temperature of $25^{\circ} \mathrm{C}$ and initial solution $\mathrm{pH} 2.5$, leading to the dissolution of the phosphorus oxide formed. This involved using 
acid leaching process to remove phosphorus from the iron oxide ore in readiness for steel making process.

The aim of this work is to derive a model for quantitative analysis of the concentration of phosphorus removed relative to the final $\mathrm{pH}$ of the solution during leaching of Itakpe (Nigerian) iron oxide ore using oxalic acid solution. This derivation is embarked on in furtherance of the previous work [15].

\section{MODEL}

The solid phase (ore) is assumed to be stationary, contains the un-leached iron remaining in the ore. Hydrogen ions from the oxalic acid attack the ore within the liquid phase in the presence of oxygen.

\subsection{Model Formulation}

Experimental data obtained from research work [15] carried out at SynchroWell Research Laboratory, Enugu were used for this work. Results of the experiment as presented in report [15] and used for the model formulation are as shown in Table 1.

Computational analysis of the experimental data [15] shown in Table 1, resulted to Table 2 which indicate that;

$$
\begin{aligned}
\ln \mathrm{P} & =(\gamma+\mathrm{N} \ln \gamma) \quad \text { (approximately) } \\
\mathrm{P} & =\mathrm{e}^{(\gamma+\mathrm{N} \ln \gamma)} \quad
\end{aligned}
$$

Introducing the value of $\mathrm{N}$ into equation (7)

$$
\mathrm{P}=\mathrm{e}^{(\gamma+0.57 \ln \gamma)}
$$

Where

$\mathrm{P}=$ Concentration of phosphorus removed during leaching of iron oxide ore using oxalic acid $(\mathrm{mg} / \mathrm{Kg})$

$\mathrm{N}=0.57$; (Dissolution coefficient of phosphorus in oxalic acid solution) determined in the experiment. [15]

$\gamma=$ Final $\mathrm{pH}$ of the leaching solution at the time $\mathrm{t}$, when the concentration of phosphorus is evaluated.

Equation (8) is the derived model. 
Table1: Variation of Concentration of Phosphorus Removed with final pH of Leaching Solution [15].

\begin{tabular}{|l|l|l|}
\hline $\mathrm{M}(\mathrm{g})$ & $\gamma$ & $\mathrm{P}(\mathrm{mg} / \mathrm{Kg})$ \\
\hline 2 & 3.12 & 42.84 \\
4 & 3.19 & 59.60 \\
6 & 3.20 & 45.60 \\
8 & 3.29 & 54.20 \\
10 & 3.41 & 54.80 \\
12 & 3.63 & 75.86 \\
14 & 3.74 & 88.23 \\
16 & 3.84 & 96.50 \\
\hline
\end{tabular}

Where $\mathrm{M}=$ Mass of iron oxide ore used for the leaching process $(\mathrm{g})$

Table 2: Variation of $\ln P$ with $(\gamma+N \ln \gamma)$

\begin{tabular}{|l|l|l|}
\hline $\mathrm{M}(\mathrm{g})$ & $\ln \mathrm{P}$ & $(\gamma+\mathrm{N} \ln \gamma)$ \\
\hline 2 & 3.7575 & 3.7686 \\
4 & 4.0877 & 3.8512 \\
6 & 3.8199 & 3.8630 \\
8 & 3.9927 & 3.9688 \\
10 & 4.0037 & 4.1092 \\
12 & 4.3289 & 4.3649 \\
14 & 4.4799 & 4.4919 \\
16 & 4.5695 & 4.6069 \\
\hline
\end{tabular}

\section{BOUNDARY AND INITIAL CONDITION}

Consider iron ore in cylindrical flask $30 \mathrm{~cm}$ high containing leaching solution of oxalic acid. The leaching solution is stationary i.e (non-flowing). The flask is assumed to be initially free of attached bacteria. Initially, atmospheric levels of oxygen are assumed. Varying weights $(2-16 \mathrm{~g})$ of iron oxide ore were used as outlined in Table 1. The initial $\mathrm{pH}$ of leaching solution; 1.2 and leaching time of $3 \mathrm{hrs}$ was used for all samples. A constant leaching temperature of $25^{\circ} \mathrm{C}$ was used. Ore grain size; $150 \mu \mathrm{m}$, volume of leaching solution; 0.1 litre and oxalic acid concentration; $0.1 \mathrm{~mol} /$ litre were used. These and other process conditions are as stated in the experimental technique [15]. 
The boundary conditions are: atmospheric levels of oxygen (since the cylinder was open at the top) at the top and bottom of the ore particles in the liquid and gas phases respectively. At the bottom of the particles, a zero gradient for the liquid scalar are assumed and also for the gas phase at the top of the particles. The leaching solution is stationary. The sides of the particles are taken to be symmetries.

\section{MODEL VALIDATION}

The formulated model was validated by direct analysis and comparison of model-predicted $\mathrm{P}$ values and those obtained from experiment [15] for equality or near equality. Analysis and comparison between these $\mathrm{P}$ values reveal deviation of model-predicted $\mathrm{P}$ values from those of the experiment. This is believed to be due to the fact that the surface properties of the ore and the physiochemical interactions between the ore and leaching solution which were found to play vital roles during the leaching process [15] were not considered during the model formulation. This necessitated the introduction of correction factor, to bring the model-predicted $\mathrm{P}$ values to those of the experimental values.

Deviation (Dv) (\%) of model-predicted $\mathrm{P}$ values from the experimental $\mathrm{P}$ values is given by

$$
\mathrm{Dv}=\left(\frac{\mathrm{Dp}-\mathrm{DE}}{\mathrm{DE}}\right) \times 100
$$

Where

$$
\begin{aligned}
& \mathrm{Dp}=\text { Predicted } \mathrm{P} \text { values by the model } \\
& \mathrm{DE}=\text { Experimental } \mathrm{P} \text { values }
\end{aligned}
$$

Correction factor $(\mathrm{Cf})$ is the negative of the deviation i.e

$$
\mathrm{Cf}=-\mathrm{Dv}
$$

Therefore

$$
\mathrm{Cf}=-100\left(\frac{\mathrm{Dp}-\mathrm{DE}}{\mathrm{DE}}\right)
$$

Introduction of the corresponding values of $\mathrm{Cf}$ from equation (11) into the model gives exactly the corresponding experimental $P$ values [15].

\section{RESULTS AND DISCUSSION}

The derived model is equation (8). A comparison of the values of $\mathrm{P}$ from the experiment and those from the model shows a maximum deviation less than $22 \%$ which is quite within the acceptable deviation limit of experimental results. The validity of the model is believed to be rooted in equation (6) where both sides of the equation are correspondingly approximately equal. Table 2 also agrees with equation (6) following the values of $\ln P$ and $(\gamma+N \ln \gamma)$ obtained following statistical and computational analysis carried out on Table 1.

Phosphorus removed per unit mass of iron oxide ore added during the leaching process was determined following comparison of the concentration of phosphorus removed per unit mass of 
iron oxide ore (added) obtained by calculations involving experimental results as well as derived model.

\subsection{Determination of the Concentration of Phosphorus Removed per Unit Mass of Iron Oxide Ore Added}

Concentration of phosphorus removed during leaching in oxalic acid solution per unit mass $\mathrm{P}_{\mathrm{m}}$ $(\mathrm{mg} / \mathrm{kg} / \mathrm{g})$ is calculated from the equation;

$$
\mathrm{P}_{\mathrm{m}}=\mathrm{P} / \mathrm{m}
$$

Therefore, a plot of concentration of phosphorus removed against mass of iron oxide ore added (as in Fig.1) gives a slope, $\mathrm{S}$ at points $(96.5,16)$ and $(42.84,2)$ following their substitution into the mathematical expression;

$$
\mathrm{S}=\Delta \mathrm{P} / \Delta \mathrm{m}
$$

Eqn. (13) is detailed as

$$
\mathrm{S}=\mathrm{P}_{2}-\mathrm{P}_{1} / \mathrm{m}_{2}-\mathrm{m}_{1}
$$

Where

$\Delta \mathrm{P}=$ Change in the concentrations of phosphorus removed $\mathrm{P}_{2}, \mathrm{P}_{1}$ at mass values $\mathrm{m}_{2}, \mathrm{~m}_{1}$. Considering the points $(96.5,16)$ and $(42.84,2)$ for $\left(\mathrm{P}_{2}, \mathrm{~m}_{2}\right)$ and $\left(\mathrm{P}_{1}, \mathrm{~m}_{1}\right)$ respectively, and substituting them into eqn. (14), gives the slope as $3.8329 \mathrm{mg} / \mathrm{kg} / \mathrm{g}$ which is the concentration of phosphorus removed per unit mass added during the actual experimental leaching process.

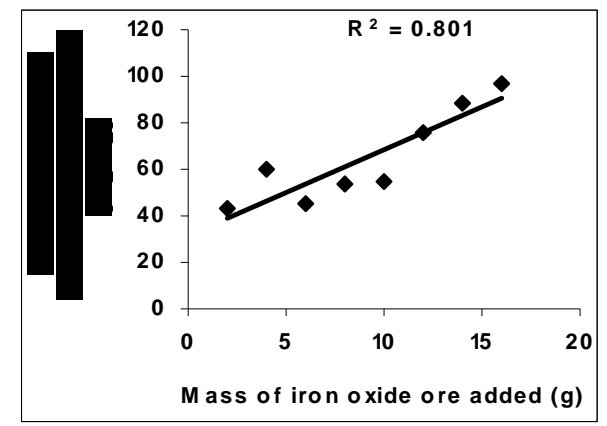

Fig.1-Effect of mass of iron oxide ore (added) on the concentration of phosphorus removed as obtained from experiment [15].

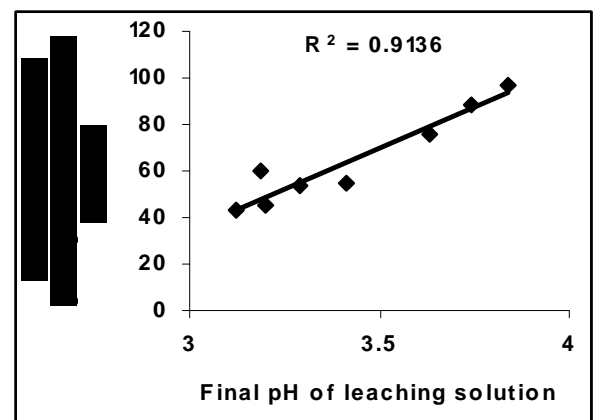

Fig.2-Effect of final $\mathrm{pH}$ on the concentration of phosphorus removed as obtained from experiment [15], 
Also similar plot (as in Fig. 2) using model-predicted results gives a slope. Considering points $(100.18,16)$ and $(43.32,2)$ for $\left(\mathrm{P}_{2}, \mathrm{~m}_{2}\right)$ and $\left(\mathrm{P}_{1}, \mathrm{~m}_{1}\right)$ respectively and substituting them into eqn. (14) gives the value of slope, $\mathrm{S}$ as $4.0614 \mathrm{mg} / \mathrm{kg} / \mathrm{g}$. This is the model-predicted concentration of phosphorus removed per unit mass of iron oxide ore used for the leaching process. A comparison of these two values of removed phosphorus concentrations per unit mass of iron oxide ore used shows proximate agreement. This indicates a very high degree of validity for the model.

An ideal comparison of the concentration of phosphorus removed per unit mass of iron oxide ore used as obtained from experiment and as predicted by the model for the purpose of testing the validity of the model is achieved by considering the $\mathrm{R}^{2}$ values. The values of the correlation coefficient, $\mathrm{R}$ calculated from the equation;

$$
\mathrm{R}=\sqrt{ } \mathrm{R}^{2}
$$

using the r-squared values (coefficient of determination) from Figs.1-4 show a very close correlation;(0.8950),(0.9558) for Figs. $1 \& 2$ and (0.9108),(0.9673) for Figs. $3 \& 4$ between values of the concentration of phosphorus removed obtained from experiment and derived model respectively. This also shows that the model-predicted concentrations of phosphorus removed are very much in proximate agreement with the corresponding concentration of phosphorus removed obtained from experiment [15]. Fig.4 shows that final $\mathrm{pH}$ contributed more significantly to the validity of the model compared with the mass of iron oxide ore added (Fig.3). This is shown in their respective $\mathrm{R}^{2}$ values.

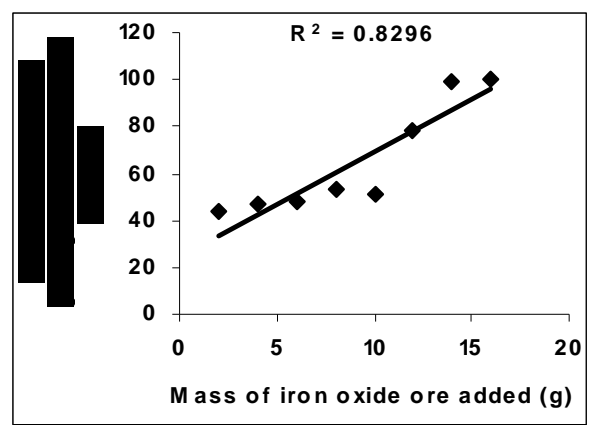

Fig.3-Effect of mass of iron oxide ore (added) on the concentration of phosphorus removed as predicted by derived model

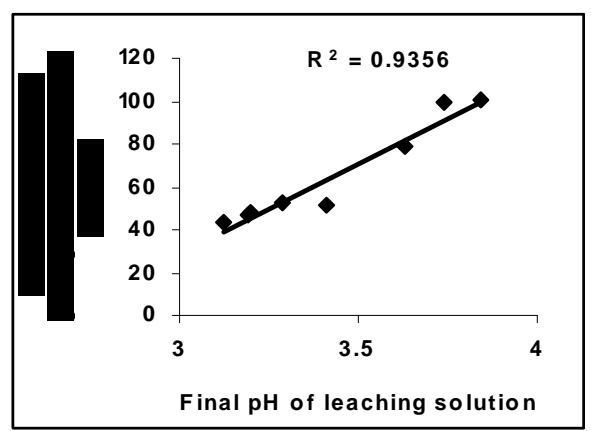

Fig.4-Effect of final $\mathrm{pH}$ on the concentration of phosphorus removed as predicted by derived model 
Comparison of Figs. 5 and 6 show that both values of the concentration of phosphorus removed obtained from the experiment [15] (line ExD) and the derived model (line MoD) in relation to both the mass of iron oxide ore (added) and final solution $\mathrm{pH}$ are generally quite close hence depicting proximate agreement and validity of the model.

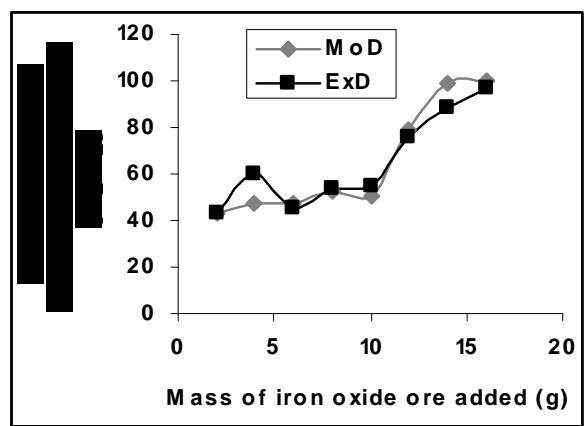

Fig.5-Comparison of the concentrations of phosphorus removed in relation to mass of iron oxide ore (added) as obtained from experiment [15] and derived model

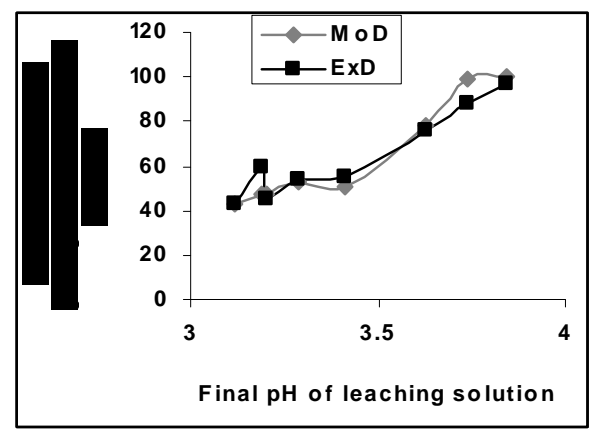

Fig.6-Comparison of the concentrations of phosphorus removed in relation to final $\mathrm{pH}$ as obtained from experiment [15] and derived model

\subsection{Effect of Mass of Iron Oxide Ore (added) on the Deviation (from Experimental Values) of Model-Predicted Concentration of Phosphorus Removed}

It was found that the validity of the model is rooted in the expression $\mathrm{P}=\mathrm{e}^{(\gamma+0.57 \ln \gamma)}$ where both sides of the expression are correspondingly approximately equal. Table 2 also agrees with equation (6) following the values of $\mathrm{P}$ and $\mathrm{e}^{(\gamma+0.57 \ln \gamma)}$ evaluated from Table 1 as a result of the corresponding computational analysis. The maximum deviation of the model-predicted concentration of phosphorus removed from the corresponding experimental value is $22 \%$ which is quite within the acceptable deviation range of experimental results, hence depicting the usefulness of the model. 
Table 3 indicates that the highest and least deviations; $-21.06 \%$ and $1.12 \%$ corresponds to the model-predicted concentrations of removed phosphorus: 47.05 and $43.32 \mathrm{mg} / \mathrm{kg}$ respectively. Table 3 also shows that these percent deviations also correspond to the mass of iron oxide ore used: 4 and $2 \mathrm{~g}$ as well as final leaching solution $\mathrm{pH} 3.19$ and 3.12 respectively.

\subsection{Effect of Mass of Iron Oxide Ore (Added) on the Correction Factor to the Model- Predicted Concentration of Phosphorus Removed}

Table 3 shows that the highest and least correction factors (21.06 and $-1.12 \%)$ which are same in also corresponds the model-predicted concentrations of removed phosphorus: 47.05 and 43.32 $\mathrm{mg} / \mathrm{kg}$ respectively, the mass of iron oxide ore used: 4 and $2 \mathrm{~g}$ as well as final leaching solution $\mathrm{pH} 3.19$ and 3.12 respectively. Table 3 also shows that the values of the correction factor are opposite that of the deviation. This is attributed to the fact that correction factor is the negative of the deviation as shown in eqns. (10) and (11). It is believed that the correction factor takes care of the effects of the surface properties of the ore and the physiochemical interaction between the ore and the leaching solution which (affected experimental results) were not considered during the model formulation.

Table 3: Comparison between concentrations of phosphorus removed as predicted by the model and as obtained from the experiment.

\begin{tabular}{|l|l|}
\hline Dv $(\%)$ & Cf $(\%)$ \\
\hline+1.12 & -1.12 \\
-21.06 & +21.06 \\
+4.41 & -4.41 \\
-2.36 & +2.36 \\
-7.12 & +7.12 \\
+3.66 & -3.66 \\
+12.54 & -12.54 \\
+3.81 & -3.81 \\
\hline
\end{tabular}

Where $\quad \mathrm{P}_{\mathrm{exp}}=$ Experimental $\mathrm{P}$ values

$\mathrm{P}_{\mathrm{M}}=$ Model-predicted $\mathrm{P}$ values

\section{CONCLUSION}

The model is useful for the quantitative analysis of the concentration of phosphorus removed during leaching of Itakpe iron oxide ore in oxalic acid solution. It was observed that the validity of the model is rooted in the expression $\ln \mathrm{P}=(\gamma+\mathrm{N} \ln \gamma)$ where both sides of the expression are correspondingly approximately equal. The model is dependent on the value of the final $\mathrm{pH}$ of the leaching solution which varies with leaching time.

Further works should incorporate more process parameters into the model with the aim of reducing the deviations of the model- predicted $\mathrm{P}$ values from those of the experimental. 


\section{ACKNOWLEDGEMENT}

The author thanks Dr. Andrew Ukoh, a modelling expert at Linkwell Modelling Centre Calabar for his technical inputs. The management of SynchroWell Nig. Ltd. Enugu is also appreciated for permitting and providing the experimental data used in this work.

\section{REFERENCES}

[1] Turkdogan, E.T., Pearson, J. (1953) J. Iron and Steel Inst., 221, pp. 393-401.

[2] Decker, A., Sevrin, R., Scimar, R. (1962) Open Hearth Proceedings, 45, pp. 421- 456.

[3] Duke, D. A., Ramstad, H. F., Meyer, H. W. (1962) Open Hearth Proceedings, vol 45, pp.8198.

[4] Kootz,T., Neuhaus, H. (1961) Stahl u. Eisen, 81, pp. 1810-1815.

[5] Kootz, K., Behrens,K., Maas, H., Baumgarten,. P. (1965) Stahl u. Eisen, 85, pp 857-865.

[6] Edneral, F. P. (1979) Electrometallurgy of Steel and Ferro-alloys, MIR Publisher, $5^{\text {th }}$ edition Moscow. pp 30-239.

[7] Zea,Y. K. (1945) J. Iron and Steel Inst., 151, pp. 459-504.

[8] Nwoye, C. I. (2008) Model for predicting the Time of Dissolution of Pre-quantified Concentration of Phosphorus during Leaching of Iron Oxide Ore in Oxalic Acid. Inter. J. Nat. Appl. Sc., 4(3):168-174.

[9] Nwoye, C. I. (2006) SynchroWell Research Work Report, DFM Unit, No 2561178, 66-83.

[10] Nwoye, C. I., Agu, P. C., Mark, U., Ikele, U. S., Mbuka, I. E., and Anyakwo, C. N. (2008) Model for Predicting Phosphorus Removal in Relation to Weight of Iron Oxide Ore and $\mathrm{pH}$ during Leaching with Oxalic Acid. Inter. J. Nat. Appl. Sc., 4(3): 292-298.

[11] Nwoye, C. I. (2009) Model for Evaluation of the Concentration of Dissolved Phosphorus during Leaching of Iron Oxide Ore in Oxalic Acid Solution. JMMCE,8(3):181-188

[12] Nwoye, C. I. (2009) Model for Predicting the Concentration of Phosphorus Removed during Leaching of Iron Oxide Ore in Oxalic Acid Solution. J. Eng. \& Appl. Sc. (in press)

[13] Nwoye, C. I. and Ndlu, S. (2009) Model for Predictive Analysis of the Concentration of Phosphorus Removed during Leaching of Iron Oxide Ore in Sulphuric Acid Solution JMMCE, 8(4):261-270.

[14] Anyakwo, C. N., and Obot, O.W. (2008) Phosphorus Removal from Nigeria`s Agbaja Iron Ore by Aspergillus niger, IREJEST 5(1), 54-58.

[15] Nwoye, C. I. (2003) SynchroWell Research Work Report, DFM Unit, No 2031196, 26-60. 